\title{
Sources of essential fatty acids in the marine microbial loop
}

\author{
Natalia V. Zhukova*, Vladimir I. Kharlamenko \\ Institute of Marine Biology, Far East Branch, Russian Academy of Sciences, Vladivostok 69004 1, Russia
}

\begin{abstract}
In the microbial loop, organic matter, irrespective of its origin and composition, is incorporated in the food chains only after it has been converted into bacterial biomass. The absence of polyunsaturated fatty acids (PUFAs) in bacteria leads to the loss of these components in the initial link of the microbial loop. This results in significant differences in the nutritional value of the initial links of food webs and the microbial loop with respect to essential fatty acids. We investigated the fatty acid composition and the capability of biosynthesizing PUFAs in marine zooflagellates and ciliates that constitute links of the microbial loop. The composition of marine zooflagellate Bodo sp. varied with substrate but in all experiments flagellates contained PUFAs. Bodo sp. is capable of synthesizing PUFAs, and 22:6(n-3) synthesis rates were especially high. The ciliate Euplotes crassus was found to contain essential fatty acids. Despite the fact that synthesis rates of PUFAs in ciliates were markedly lower compared to that in zooflagellates, the occurrence of essential fatty acids in ciliates further enriches the biochemical composition of the microbial loop. It was shown that flagellates and ciliates are the source of PUFAs in the microbial loop. This compensates for the drawbacks of the microbial loop, connected with the specific biochemical composition of bacteria.
\end{abstract}

KEY WORDS: Food webs - Microbial loop - Polyunsaturated fatty acids - Biosynthesis - Zooflagellate Ciliate

\section{INTRODUCTION}

Organic matter formed in the marine ecosystems by photosynthetic organisms is utilized either directly in the food web ('classical' [Steel 1974] and microbial) or through the microbial loop (Azam et al.1983). In a food web, the photosynthetic organisms themselves are consumed. Marine animals are thereby supplied with essential fatty acids which they are unable to synthesize in sufficient amounts to cover their physiological needs (Watanabe et al. 1983). Only plants have been shown to be capable of synthesizing $18: 3(n-3)$ and 18:2(n-6) acids de novo in marine ecosystems. $n-3$ and $\mathrm{n}-6$ polyunsaturated fatty acids (PUFAs) with more than 18 carbon atoms are primarily produced by microand macroalgae and are transferred via the food chain to the higher animals (Sargent \& Whittle 1981, Fraser et al. 1989).

•E-mail:nzhuk@biom.marine.su
In the microbial loop, organic matter, irrespective of its origin and composition, is incorporated into the food chains only after it has been converted into bacterial biomass. Unlike micro- and macroalgae, most bacteria do not contain PUFAs (Wilkinson 1988), although there are reports regarding the detection of PUFAs in some bacterial species (Johns \& Perry 1977, DeLong \& Yayanos 1985, Yazawa et al. 1988). The absence of PUFAs in bacteria leads to the loss of these components in the initial link of the microbial loop. This results in significant differences in the nutritional value of the initial links of food web and microbial loop with respect to PUFAs. The food chain devoid of PUFAs is merely an addition to another food chain, but it is not a proper food chain.

Aside from the bacterial link, the microbial loop differs from the 'classical' food chain in having additional links comprised of bactivorous zooflagellates and ciliates (Pomeroy 1974, Sorokin 1978). In the intermediate links, significant losses of matter and energy occur (Newell 
1984). In our opinion, these losses are, to some extent, compensated if the intermediate links are the source of PUFAs in the microbial loop, which make the loop comparable with the 'classical' food web in this respect.

In this work, we investigated the fatty acid composition and the capability of biosynthesizing PUFAs in zooflagellates and ciliates that may constitute links of the microbial loop.

\section{MATERIALS AND METHODS}

The kinetoplastid flagellate Bodo sp. was isolated from the water of Amursky Bay, the Sea of Japan. The hypotrich ciliate Euplotes crassus was isolated from sand of Vostok Bay, the Sea of Japan. The medium consisted of freshly collected filtered $(0.2 \mu \mathrm{m}$, Millipore) seawater enriched with $1 \mathrm{~g} \mathrm{l}^{-1}$ rice or $1 \mathrm{~g} \mathrm{l}^{-1}$ starch gel. Ciliates and flagellates were grown in 1 to 31 glass vessels at room temperature in the dark. For lipid analysis and biosynthetic study, flagellate cultures were prefiltered through a $30 \mu \mathrm{m}$ mesh gauze and collected on a $2 \mu \mathrm{m}$ lavsane membrane filter. The ciliate cultures were prefiltered through a $100 \mu \mathrm{m}$ mesh gauze and concentrated on a $20 \mu \mathrm{m}$ mesh gauze. Filters with flagellates or slides with a drop of seawater containing ciliates were examined using epifluorescent microscopy for the detection of extragenous microorganisms. Lipids were extracted with chloroform-methanol, $1: 1(\mathrm{v} / \mathrm{v})$ by the method of Bligh \& Dyer (1959) and transesterified according to the method of Carreau \& Dubacq (1978). Fatty acid methyl esters (FAMEs) were purified by thin-layer chromotography (TLC) using benzene as solvent. The resulting FAMEs were analyzed by gas chromatography using a Shimadzu GC-9A chromatograph equipped with a flame ionization detector and a Supelcowax 10 fused-silica capillary column ( $30 \mathrm{~m} \times 0.25 \mathrm{~mm}$ i.d.). Helium was used as a carrier gas, and split ratio was 1:60. The column and injector temperatures were 210 and $240^{\circ} \mathrm{C}$, respectively. Individual FAME peaks were identified by comparing $\mathrm{R}_{\mathrm{t}} \mathrm{S}$ (retention times) with those for authentic standards and using Equivalent Chain Length values (Christie 1988). Additionally, AgNO3TLC was used for the identification of unsaturated fatty acids. Peak area percentages were obtained with a Shimadzu integrator Chromatopac CR-3A.

The biosynthesis of the fatty acids was studied using the concentrated culture of the ciliate Euplotes crassus or the flagellate Bodo sp. grown on rice. Sodium $1{ }^{14} \mathrm{C}$ labelled acetate (Isotop, Russia) was dissolved in filtered seawater $(0.2 \mu \mathrm{m}$. Millipore). Twenty $\mu \mathrm{Ci}(0.1 \mu \mathrm{Ci}$ $\mu^{-1}$ ) sodium $1-{ }^{14} \mathrm{C}$ acetate was used in each experiment. Protozoa were incubated for $24 \mathrm{~h}$ at room temperature in the dark. After incubation, the cultures were sedimented on lavsane membrane filters. Filters with protozoa were washed with additional cold acetate to remove the non-specifically bound label and placed in glass vials containing a chloroform-methanol mixture, 1:1 ( $/ \mathrm{v})$. Lipids were extracted as indicated above. Labelled lipids were separated by TLC using hexane-diethyl ether-acetic acid, 85:15:1 (v/v) as developing solvents. To detect the radioactivity of individual fatty acids, labelled FAMEs were analyzed by 2 dimensional TLC, combined with TLC on silica gel impregnated with silver nitrate in the first direction, and reversed-phase chromatography in the second direction. (Svetashev \& Zhukova 1985). The zones of silica gel containing methyl esters made visible with iodine vapour were transferred into flasks where $1 \mathrm{ml}$ of the scintillation fluid was added. The scintillation fluid contained $5 \mathrm{~g}$ PPO (2,5-diphenyloxazole) $\mathrm{I}^{-1}$ toluene with $3 \%$ methanol. Radioactivity was measured with an SL-30 liquid scintillation spectrometer (Intertechnique, France) with a fully open window. Simultaneously, the same labelled methyl esters of protozoa were analyzed by gas-liquid chromotography (GLC) to determine the percentage of the fatty acids. The relative specific activities of labelled fatty acids were calculated as the ratio of percent of total fatty acid radioactivity to percent of total ${ }^{14} \mathrm{C}$ fatty acid mass.

\section{RESULTS}

At the beginning of incubation, the lipid composition of organic matter corresponds with the composition of rice or starch. Along with saturated and monounsaturated fatty acids, the constituent PUFA of rice was $18: 2(n-6)(31 \%)$, and the constituent PUFA of starch 18:2(n-6) (20.8\%) and 18:3(n-3) (14\%). The long chain PUFAs (longer then C18) were absent in lipids of rice and starch. Bacteria that initially grew on rice or starch were separated from the substrate and their fatty acids were analyzed. The acid 16:0 was dominant and accounted for $27 \%$ of the total fatty acids. Significant concentrations of $16: 1(n-7), 18: 0$, $18: 1(n-9)$, and $18: 1(n-7)$ (each about $10 \%)$ were determined. Typical bacterial odd chain length and branched fatty acids were also found. After a weck of incubation, various long-chain PUFAs were found in the lipids of the incubation mixture. This is due to the development of a large number of flagellates and ciliates. Branched and cis-vaccenic fatty acids characteristic of bacteria made up a significant percentage of the total fatty acids.

The major fatty acids in isolated ciliates were saturated and monounsaturated acids (Table 1, Fig 1A). The concentration of PUFAs was $17.4 \%$ for ciliates fed on rice-grown bacteria and $7.2 \%$ for ciliates fed on 
Table 1 Fatty acid composition (wt \%) of zooflagellate Bodo sp. and ciliate Euplotes crassus. Data are average \pm standard deviation

\begin{tabular}{|c|c|c|c|c|}
\hline $\begin{array}{l}\text { Fatty } \\
\text { acids }^{\mathrm{a}}\end{array}$ & $\begin{array}{c}\text { Bodo sp. } \\
\text { (rice) } \\
(n=3)\end{array}$ & $\begin{array}{c}\text { Bodo sp. } \\
\text { (starch) } \\
(n=4)\end{array}$ & $\begin{array}{c}\text { E. crassus } \\
\text { (starch) } \\
(n=4)\end{array}$ & $\begin{array}{c}\text { E. crassus } \\
\text { (rice) } \\
(n=6)\end{array}$ \\
\hline $12: 0$ & $1.4 \pm 0.5$ & $1.5 \pm 0.2$ & $1.3 \pm 0.4$ & $0.9 \pm 0.2$ \\
\hline $14: 0$ & $5.3 \pm 0.2$ & $8.1 \pm 0.5$ & $5.0 \pm 0.1$ & $4.4 \pm 1.0$ \\
\hline $14: 1$ & $1.6 \pm 0.2$ & $1.8 \pm 0.1$ & $1.7 \pm 0.2$ & $1.6 \pm 0.2$ \\
\hline $15: 0$ & $2.7 \pm 0.2$ & $2.5 \pm 0.3$ & $2.7 \pm 0.2$ & $2.7 \pm 0.7$ \\
\hline $15: 1$ & $1.1 \pm 0.2$ & $1.4 \pm 0.2$ & $1.1 \pm 0.1$ & $1.2 \pm 0.2$ \\
\hline $15: 0-i$ & $2.6 \pm 1.1$ & $0.5 \pm 0.1$ & $0.5 \pm 0.2$ & $0.9 \pm 0.0$ \\
\hline 15:0-ai & $1.1 \pm 0.2$ & $0.8 \pm 0.2$ & $1.0 \pm 0.2$ & $1.6 \pm 0.1$ \\
\hline $16: 0$ & $22.8 \pm 2.1$ & $21.4 \pm 0.7$ & $25.3 \pm 1.5$ & $20.3 \pm 4.3$ \\
\hline $16: 1(n-9)$ & $6.2 \pm 1.4$ & $8.3 \pm 0.4$ & $8.0 \pm 1.8$ & $6.7 \pm 1.4$ \\
\hline $16: 1(n-7)$ & $4.4 \pm 1.4$ & $6.9 \pm 1.3$ & $3.6 \pm 2.4$ & $6.8 \pm 1.4$ \\
\hline $17: 0$ & $1.1 \pm 0.1$ & $0.9 \pm 0.1$ & $1.1 \pm 0.1$ & $1.2 \pm 0.4$ \\
\hline $17: 1$ & $1.1 \pm 0.1$ & $1.2 \pm 0.1$ & $1.1 \pm 0.2$ & $1.3 \pm 0.2$ \\
\hline $18: 0$ & $11.0 \pm 1.8$ & $8.2 \pm 1.2$ & $9.4 \pm 1.5$ & $6.6 \pm 1.1$ \\
\hline $18: 1(\mathrm{n}-9)$ & $10.9 \pm 1.7$ & $11.4 \pm 0.1$ & $16.1 \pm 4.0$ & $10.2 \pm 0.1$ \\
\hline $18: 1(n-7)$ & $7.5 \pm 2.3$ & $2.9 \pm 0.4$ & $3.7 \pm 0.9$ & $6.2 \pm 1.1$ \\
\hline $18: 2(n-6)$ & $2.9 \pm 0.2$ & $3.5 \pm 0.4$ & $5.2 \pm 0.1$ & $4.9 \pm 0.3$ \\
\hline $20: 2(n-6)$ & $1.6 \pm 0.6$ & $0.8 \pm 0.2$ & $0.8 \pm 0.2$ & $1.0 \pm 0.6$ \\
\hline $20: 4(n-6)$ & 0 & 0 & $0.4 \pm 0.3$ & $4.8 \pm 1.2$ \\
\hline $20: 5(n-3)$ & $0.5 \pm 0.3$ & $0.6 \pm 0.2$ & $0.5 \pm 0.3$ & $2.3 \pm 0.6$ \\
\hline $22: 6(n-3)$ & $0.8 \pm 0.5$ & $5.8 \pm 1.1$ & 0 & $0.7 \pm 0.2$ \\
\hline
\end{tabular}

starch-grown bacteria (Fig. 1A). Ciliates grown in the rice culture contained $20: 4(n-6)(4.8 \%)$ and $20: 5(n-3)$ $(2.3 \%)$ (Fig. 2B). Ciliates cultivated in the starch culture had a low content of PUFAs.

The constituent PUFAs of flagellates grown in the rice culture were $\mathrm{C} 18$ and $\mathrm{C} 20$ which comprised $5.9 \%$ (Table 1). Among these, the dienoic fatty acids 18:2(n-6) and 20:2(n-6) were dominant (Fig. 1B). The yield of PUFAs was greater $(10.7 \%)$ for flagellates cultivated on starch-grown bacteria. Of special note is the presence of 22:6(n-3) in flagellates (Fig. 1B).
Biosynthesis was investigated using $1{ }^{14} \mathrm{C}$ acetate. The distribution of radioactivity from acetate among different lipid classes is shown in Fig. 2A. In both flagellates and ciliates, labelled acetate was most actively incorporated in phospholipids. Moreover, significant levels of radioactivity were found in triacylglycerides and free fatty acids of flagellates (Fig. 2A). In ciliates, the greater portion of the total radioactivity was detected in the saturated and monounsaturated acids, while in flagellates the acid 22:6(n-3) was intensively labelled (Fig. 2B). A comparison of the relative specific activity of the fatty acids showed that flagellates synthesized saturated and monounsaturated fatty acids as well as PUFAs at high rates. Among the PUFAs, 20:5(n-3) and 22:6(n-3) exhibited the highest relative specific activities. Ciliates intensively synthesized only saturated and monounsaturated fatty acids (Fig. 2 C).

\section{DISCUSSION}

Up to now, there has been some uncertainty regarding the fate of PUFAs in the microbial loop because of the lack of data on the content of PUFAs in marine zooflagellates and ciliates (Phillips 1984, Stoecker \& Capuzzo 1990). The results of this study suggest that zooflagellates and ciliates that constitute the links following bacteria in the microbial loop contain PUFAs and are able to synthesize these essential components.

Flagellates are the dominant group of marine heterotrophic nanoplankton with respect to abundance, biomass, and diversity (Fenchel 1987). An important property of zooflagellates is the ability to effectively capture bacteria and they represent the major consumers of bacterial biomass in the marine ecosystems. Another important feature is that zooflagellates are capable of synthesizing PUFAs. Among zooflagellates,
Fig. 1. Distribution of (A) saturated, monounsaturated and polyunsaturated fatty acids and (B) individual polyunsaturated fatty acids of flagellate Bodo sp. and ciliate Euplotes crassus cultivated on rice $(\mathrm{R})$ or starch (S) as \% of the total fatty acids
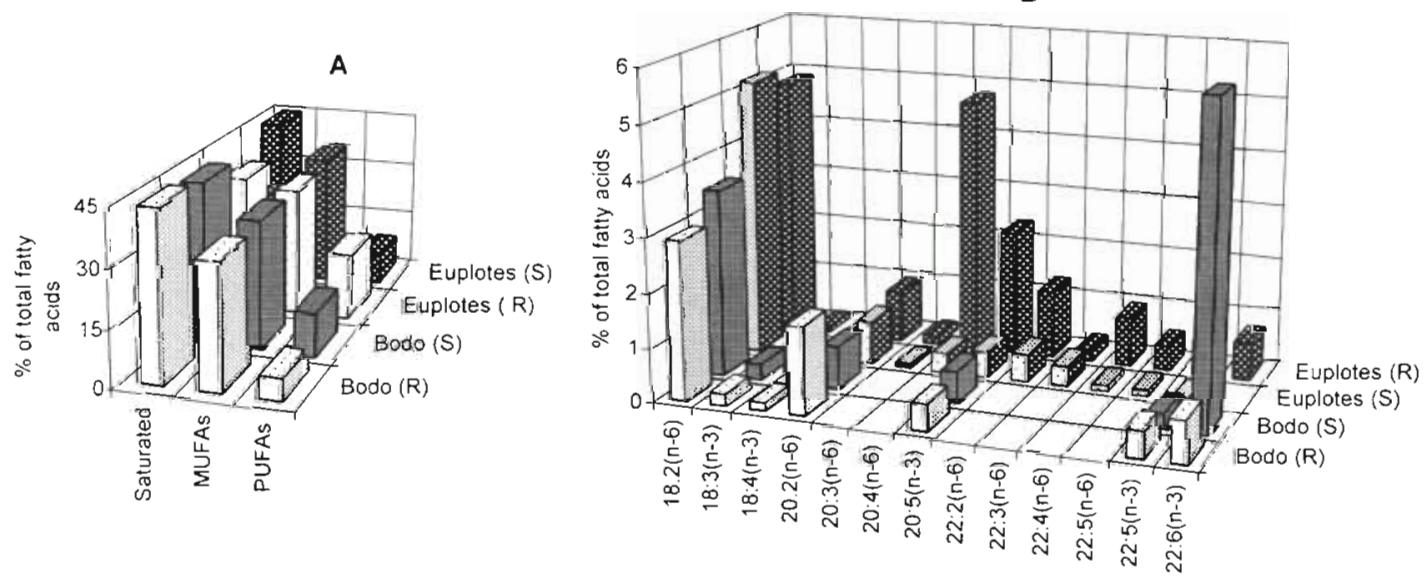

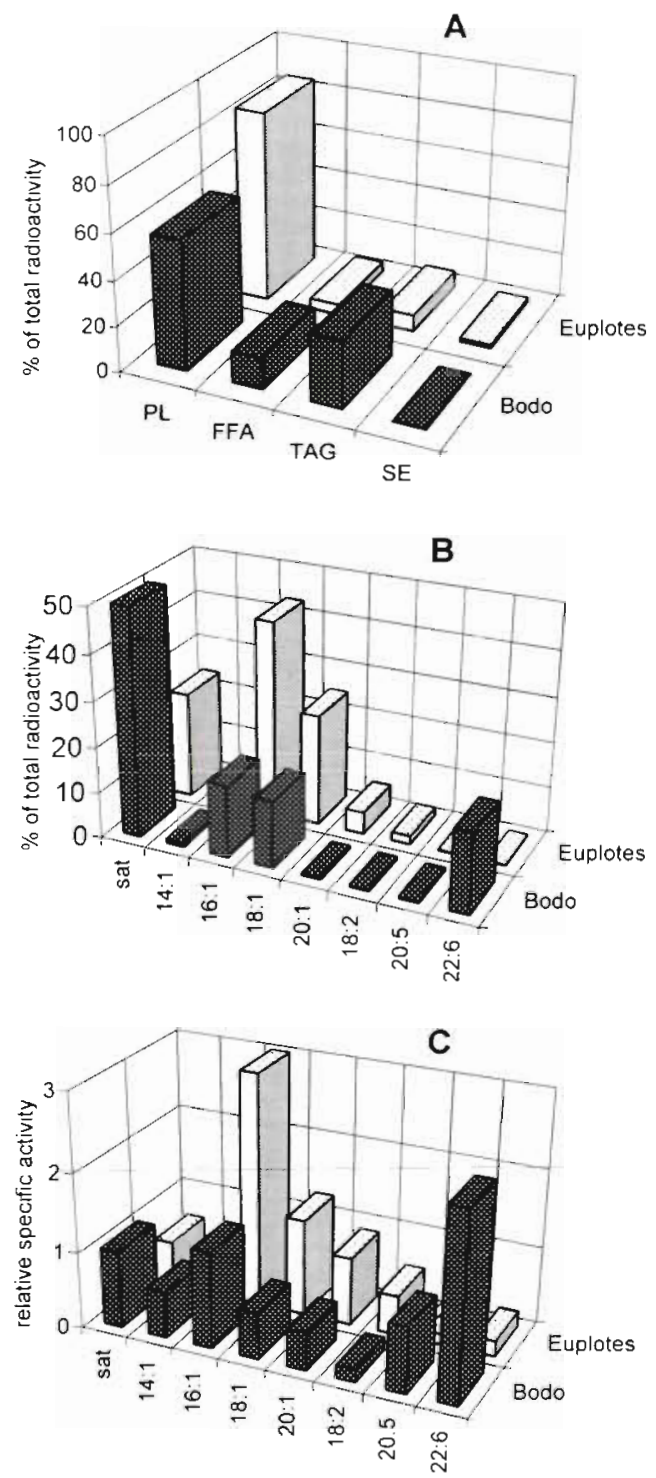

Fig. 2. Distribution of radioactivity from $1-{ }^{14} \mathrm{C}$ acetate among (A) lipid classes and (B) fatty acids of protozoa cultivated on rice. The total radioactivity was $100 \%$. (C) Relative specific activity of protozoan fatty acids. PL: polar lipids; FFA: free fatty acids; TAG: triacylglycerols; SE: sterol esters

the fatty acid composition is known only in parasitic species (Erwin 1973). We investigated the composition of the free-living marine zooflagellates Bodo sp. cultured on various substrates. The composition of this species varied with substrate but in all experiments fiagellates contained PUFAs. The experiments revealed that flagellates are capable of synthesizing PUFAs and that synthesis rates were especially high for 22:6(n-3) acid. Owing to the presence of and the ability of zooflagellates to synthesize long-chain PUFAs, the microbial loop can be considered equal to the 'classical' food web with respect to essential fatty acids.
Zooflagellates are the major consumers of bacteria in most of the marine ecosystems. However, in some ecosystems small aloricate ciliates can be the major consumers of bacteria (Sherr et al. 1986). Small aloricate ciliates of the order Scuticociliatida grew abundantly in a number of cultures during our experiments. Lipid analysis of these aloricate ciliates showed that members of this order contained up to $22.2 \%$ of PUFAs. The following acids accounted for more than $1 \%: \quad 18: 2(n-6), \quad 18: 4(n-3), \quad 20: 4(n-6), 20: 5(n-3)$ and $22: 6(n-3)$. The results suggest that no significant depletion of PUFAs occurs in the microbial loop when small aloricate ciliates rather than zooflagellates follow the bacterial link.

In many marine ecosystems, flagellates are consumed by ciliates in the food chain. The fatty acid composition is known for parasitic ciliates, ciliates isolated from ruminants, and freshwater ciliates, mostly of the genus Paramecium (Katz \& Keeney 1967, Erwin 1973, Kaneshiro 1987). All these ciliates contain PUFAs but the $n-3$ acids occur in small concentrations. Among marine ciliates, significant amounts of PUFAs were detected for the tintinnid Stenosemella ventricosa. It should be emphasized that $S$. ventricosa was fed on phytoplankton and contained fatty acids common to dinoflagellates and cryptomonads (Claustre et al. 1988/1989), i.e. it represents a component of the 'classical' food chain. The ciliate E. crassus contains essential fatty acids (Table 1). In the 'classical' chain, these fatty acids occur in diatoms and a variety of other algae. Despite the fact that synthesis rates of PUFAs in ciliates were markedly lower compared to that of zooflagellates, the occurrence of PUFAs in ciliates further enriches the biochemical composition of the microbial loop. Quite recently the lipid and fatty acid composition of a marine ciliate Parauronema acutum grown in pure culture were reported. Its total lipids contained significant level of PUFAs: 18:4(n-3) $19 \%$ of the total fatty acids), $20: 5(n-3)(10 \%)$ and $22: 6(n-3)$ (5\%) (Sul \& Erwin 1997). Very likely, conditions under which we cultivated flagellates and ciliates did not allow them to synthesize PUFAs at maximun rate. The amount and composition of PUFAs may be related to the species composition of protozoa and environmental ronditions: however, the same holds true for the initial links of the food chains.

The question as to whether or not protozoa can be the source of PUFAs in the marine chains has been discussed in the literature (Phillips 1984, Stoecker \& Capuzzo 1990). Our study suggests that zooflagellates and ciliates can be a source of PUFAs in the microbial loop. Thus, while the microbial loop may be an inefficient pathway of carbon transfer, the organic matter packaged in the form of bacteriovores may be richer in biochemical composition. 


\section{LITERATURE CITED}

Azam F, Fenchel T, Field JG, Gray JS, Meyer-Reil LA, Thingstad F (1983) The ecological role of water column microbes in the sea. Mar Ecol Prog Ser 10:257-263

Bligh EG, Dyer WJ (1959) A rapid method of total lipid extraction and purification. Can J Biochem Physiol 37:911-917

Carreau JP, Dubacq JP (1978) Adaptation of macro-scale method to the micro-scale for fatty acid methyl transesterification of biological extracts. J Chromatogr 151 $384-390$

Christie WW (1988) Equivalent chain-lengths of methyl ester derivatives of fatty acids on gas chromatography. J Chromatogr 447:305-314

Claustre H, Marty JC, Cassiani L, Dagaut J (1988/1989) Fatty acid dynamics in phytoplankton and microzooplankton communities during a spring bloom in the coastal Ligurian Sea: ecological implications. Mar Microb Food Webs 3 : $51-66$

DeLong EF, Yayanos AA (1985) Biochemical function and ecological significance of novel bacterial lipids in deepsea procaryotes. Appl Environ Microbiol 51:730-737

Erwin JA (1973) Comparative biochemistry of fatty acids in eukaryotic microorganisms. In: Erwin JA (ed) Lipids and biomembranes of eucaryotic microorganisms. Academic Press, New York, p 42-143

Fenchel T (1987) Ecology of Protozoa. Science Technical Publishers, Madison, WI

Fraser AJ, Sargent JR, Gamble JC, Seaton D (1989) Formation and transfer of fatty acids in an enclosed marine food chain comprising phytoplankton, zooplankton and herring (Clupea harengus) larvae. Mar Chem 27:1-78

Johns RB, Perry GY (1977) Lipids of marine bacterium Flexibacter polymorphus. Arch Microbiol 114:267-271

Katz I, Keeney M (1967) The lipids of rumen holotrich Protozoa. Biochim Biophys Acta 144:102-112

Kaneshiro ES(1987) Lipids of Paramecium. J Lipid Res 28 $1241-1258$

Editorial responsibility: John Dolan,

Villefranche-sur-Mer, France
Newell RC (1984) Biological role of detritus in marine environment. In: Fasham $M$ (ed) Flow of energy and materials in marine ecosystems. Plenum Press, New York p $317-343$

Phillips NV (1984) Role of different microbes and substrates as potential suppliers of specific essential nutrients to marine detritivores. Bull Mar Sci 35:283-298

Pomeroy LR (1974) The ocean's food web: a changing paradigm. BioSci $9: 499-504$

Sargent JR, Whittle KJ (1981) Lipids and hydrocarbons in the marine food web. In: Longburst (ed) Analysis of marine ecosystems. Academic Press, London, p 491-533

Sherr EB, Sherr BF, Fallon RD, Newell SY (1986) Small, aloricate ciliates as a major component of the marine het erotrophic nanoplankton. Limnol Oceanogr 31:177-183

Sorokin YI (1978) Decomposition of organic matter and nutrient regeneration In: Kinne $O$ (ed) Marine Ecology, Vol 4, Dynamics. John Wiley, Chichester p 511-616

Steele JH (1974) The structure of marine ecosystems. Harvard University Press, Cambridge, MA

Stoecker DK, Capuzzo JMD (1990) Predation on protozoa: its importance to zooplankton. J Plankton Res 12:891-908

Sul D, Erwin JA (1997) The membrane lipids of the marine ciliated protozoan Parauronema acutum. Biochim Biophys Acta 1345:162-171

Svetashev VI, Zhukova NV (1985) Analysis of labelled fatty acid methyl esters by argentation and reversed-phase two dimensional-thin layer chromatography. J Chromatogr 330:396-399

Watanabe T, Katajima CS, Fujita S (1983) Nutritional values of live organisms used in Japan for mass propagation of fish: a review. Aquaculture 34:115-134

Wilkinson SG (1988) Gram negative bacteria. In: Ratledge C Wilkinson SG (eds) Microbial lipids, Vol 1. Academic Press, London, p 299-488

Yazawa K, Araki K, Okazaki N, Watanabe K, Ishikawa $C$, Inoue A, Numao N, Kondo K (1988) Production of eicosapentaenoic acid by marine bacteria. J Biochem 100:5-7

Submitted: May 9, 1998; Accepted: August 10, 1998

Proofs received from author(s): April 28, 1999 